\title{
Correction to: Modelling concrete and abstract concepts using brain-constrained deep neural networks
}

\author{
Malte R. Henningsen-Schomers ${ }^{1,4} \cdot$ Friedemann Pulvermüller ${ }^{1,2,3,4} \oplus$
}

Accepted: 27 January 2022 / Published online: 14 February 2022

c) Springer-Verlag GmbH Germany, part of Springer Nature 2022

Correction to: Psychological Research

https://doi.org/10.1007/s00426-021-01591-6

In the original publication of the article, there was a mistake in Eq. (7) in the Appendix. In lines 2 and 3 of the equation, it should read $V(j, t)$ instead of $V(y, t)$. Furthermore, several minor corrections to the text were made.

The original article has been corrected.

Publisher's Note Springer Nature remains neutral with regard to jurisdictional claims in published maps and institutional affiliations.

The original article can be found online at https://doi.org/10.1007/ s00426-021-01591-6.

Malte R. Henningsen-Schomers malte2011@cantab.net

1 Department of Philosophy of Humanities, Brain Language Laboratory, Freie Universität Berlin, Habelschwerdter Allee 45, 14195 Berlin, Germany

2 Berlin School of Mind and Brain, Humboldt-Universität zu Berlin, Berlin, Germany

3 Einstein Center for Neurosciences, Berlin, Germany

4 Cluster of Excellence 'Matters of Activity. Image Space Material', Humboldt-Universität zu Berlin, Berlin, Germany 